\title{
A FORMAÇÃO DOS TRABALHADORES NO ESPAÇO DE
}

\author{
TRABALHO
}

Acacia Zeneida Kuenzer ${ }^{1}$

\section{RESUMO}

Este artigo trata dos processos de formação amplamente pedagógicos, em duas dimensões - a técnica e a subjetiva, com base na categoria disciplinamento, retomado Gramsci quando afirma que a pedagogia vem da fábrica, e que toda relação hegemônica é uma relação pedagógica. Assim é que, no regime de acumulação flexível, o capital enfrenta, entre outros desafios, o de desenvolver novas subjetividades, flexíveis, que se submetam às novas formas de exploração do trabalho, agora predominantemente intelectualizado, para o que mobiliza novas formas de disciplinamento mediante processos ampla e especificamente pedagógicos, também denominados flexíveis. Com base nesses pressupostos, são apresentadas algumas das aprendizagens que os processos pedagógicos que integram as relações sociais e de trabalho, promovem. Essas aprendizagens derivam-se da negação da práxis como possibilidade de transformação, princípio que fundamenta as teorias pós-modernas: o pragmatismo utilitarista, o presentismo, a competitividade, a individualização, a fragmentação, a homogeneização das identidades, a redução do real ao virtual, a redução da ética à estética, a banalização da violência, a banalização do esforço, a passividade cognitiva e a naturalização da perda dos direitos trabalhistas.

Palavras-chave: formação de subjetividades flexíveis; educação de trabalhadores na pós-modernidade; trabalho e educação na acumulação flexível.

\section{ABSTRACT}

This article addresses wide-ranging teacher training processes in two dimensions, the technical and the subjective, based on the disciplinary category, resorting to Gramsci when he claimed that pedagogy comes from the factory, and that all hegemonic relationships are pedagogical relationships. Therefore, in a regime of flexible accumulation, capital faces, in addition to other challenges, the challenge of developing new flexible subjectivities that are submitted to new forms of exploitation of labor, which has now been predominantly intellectualized, to mobilize new forms of discipline through broad and specific pedagogical processes that are also referred to as flexible. Based on these assumptions, some of the learning that pedagogical processes that integrate social and labor relations promote. This learning is derived from the denial of praxis, as a possibility for transformation, the principle on which post-modern theories are founded. These theories includeutilitarian pragmatism, presentism, competitiveness,

\footnotetext{
${ }^{1}$ Doutora em Educação pela PUC/SP, Pesquisadora 1A do Cnpq, Professora Titular aposentada da UFPR; Professora Titular da Universidade Feevale.
}

TrabalhoNecessario - www.uff.br/trabalhonecessario; Ano 14, № 25/2016 
individualization, fragmentation, homogenization of identities, the reduction of the real to the virtual, the reduction of the ethical to the esthetic, the trivialization of violence, the trivialization of effort, cognitive passivity and the naturalization of the loss of labor rights.

Key words: formation of flexible subjectivities; education of workers in the postmodern era; work and education in flexible accumulation

\section{Introdução}

O ponto de partida para a análise da formação dos trabalhadores no espaço de trabalho é a afirmação de Marx e Engels na Ideologia Alemã, posteriormente retomada por Marx no Capital, que tomei como pressuposto na Pedagogia da Fábrica, em 1985: o homem se educa, se faz homem, na produção e nas relações de produção, através de um processo contraditório em que estão sempre presentes e em confronto, momentos de educação e de deseducação, de qualificação e de desqualificação e, portanto, de humanização e de desumanização. (Kuenzer, 1985, p.11)

Tomando como pressuposto que o conhecimento não se produz apenas nas situações escolares, mas nas relações sociais em seu conjunto, torna-se necessário diferenciar dois tipos de processo pedagógico, que se articulam mas guardam especificidades: os amplamente pedagógicos e os especificamente pedagógicos. Os processos amplamente pedagógicos são constituídos pelas dimensões educativas presentes em todas as experiências de vida social e laboral. Estas são assistemáticas, não intencionais, mas nem por isso, pouco relevantes do ponto de vista da produção do conhecimento.

Nestes processos amplamente pedagógicos inserem-se o conjunto das relações vividas no trabalho, a partir das formas de organização e gestão dos processos produtivos, que contém um projeto educativo que, embora nem sempre explícito, desempenha relevante papel de disciplinamento e de desenvolvimento intelectual e técnico dos profissionais.

Assim é que os trabalhadores, no cotidiano do trabalho, aprendem e ensinam, a partir das relações que estabelecem com outros trabalhadores, com as chefias e com os profissionais que atuam nas diferentes áreas da empresa, 
como a saúde, a gestão de pessoas, o planejamento estratégico, a área financeira, e assim por diante. Estas relações serão mais ricas de aprendizagem quanto mais as experiências e conhecimentos sejam compartilhados, na perspectiva da democratização dos saberes. Ao contrário, serão limitadas quando as relações de trabalho são excessivamente hierarquizadas e autoritárias. (Kuenzer, 2007)

Os processos especificamente pedagógicos são os intencional e sistematicamente desenvolvidos com o objetivo de possibilitar o acesso a conhecimentos, técnicas, ou dimensões culturais, produzidos pela sociedade em seu processo de desenvolvimento histórico. Estes processos têm por finalidade possibilitar a transição do senso comum e dos saberes tácitos originados das experiências empíricas para o conhecimento científico, de natureza sóciohistórica, cultural e tecnológica, o que supõe o domínio do método científico. Eles incluem a formação escolar geral e profissional e os cursos de capacitação ofertados pelas instituições específicas e pelas empresas.

Neste texto trataremos dos processos de formação amplamente pedagógicos, em duas dimensões - a técnica e a subjetiva, com base na categoria disciplinamento, retomado Gramsci quando afirma que a pedagogia vem da fábrica, e que toda relação hegemônica é uma relação pedagógica.(Gramsci,1978)

A partir de seus estudos sobre o americanismo e o fordismo, o autor demonstra a eficiência dos processos educativos na valorização do capital, à medida em que as novas formas de organização do trabalho e as relações de produção que elas geram, veiculam novas concepções e modos de vida, comportamentos, atitudes, valores. O novo tipo de produção racionalizada demandava um novo tipo de homem, capaz de ajustar-se aos novos métodos da produção, para cuja educação eram insuficientes os mecanismos de coerção social; tratava-se de articular novas competências a novos modos de viver, pensar e sentir, adequados aos novos métodos de trabalho caracterizados pela automação, ou seja, pela ausência de mobilização de energias intelectuais e criativas no desempenho do trabalho. O novo tipo de trabalho exigia uma nova concepção de mundo que fornecesse ao trabalhador uma justificativa para a sua crescente alienação e ao mesmo tempo suprisse as necessidades do capital com um homem cujos comportamentos e atitudes respondessem às suas demandas 
de valorização."É neste sentido que a hegemonia, além de expressar uma reforma econômica, assume as feições de uma reforma intelectual e moral" ( Gramsci, 1978; Kuenzer, 1985, p. 52 )

\section{Ampliar a escolaridade e apropriar-se da ciência do trabalho: o que} os trabalhadores aprendem a partir da base microeletrônica

O processo de internacionalização da economia e a reestruturação produtiva em curso, enquanto macro-estratégias responsáveis pelo novo padrão de acumulação capitalista, transformam radicalmente a forma de organização da produção, imprimindo vertiginosa dinamicidade às mudanças que ocorrem no processo produtivo, a partir da crescente incorporação de ciência e tecnologia, em busca de competitividade. A descoberta de novos princípios científicos permite a criação de novos materiais e equipamentos; os processos de trabalho de base rígida vão sendo substituídos pelos de base flexível; a eletromecânica, com suas alternativas de solução bem definidas, cedeu lugar à microeletrônica, que assegura amplo espectro de soluções possíveis desde que a ciência e a tecnologia, antes incorporadas aos equipamentos, passem a ser domínio dos trabalhadores; os sistemas de comunicação interligam o mundo da produção.

Inaugura-se um novo regime de acumulação que têm na flexibilização dos processos de trabalho, dos mercados, dos produtos e dos padrões de consumo (Harvey, 1992), uma de suas mais importantes expressões, do que decorrem novas demandas de desenvolvimento profissional para os trabalhadores, nas dimensões técnica, cognitiva complexa e comportamental. Ao invés de profissionais rígidos, competentes nos fazeres que se repetem através da memorização, há que formar profissionais flexíveis, que acompanhem as mudanças tecnológicas decorrentes da dinamicidade da produção científicotecnológica contemporânea.

Talvez a mais importante mudança trazida pelas novas bases materiais de produção seja a mudança de eixo na relação entre trabalho e educação, que deixa de priorizar os modos de fazer para contemplar a articulação entre as diferentes formas e intensidades de conhecimento, tácito e científico com foco no enfrentamento de situações não previstas. 
Com base em Zarifian (2001), pode-se afirmar que esta mudança de eixo, a partir da mediação da base microeletrônica com seus impactos nas formas de organizar o trabalho, se evidencia a partir da mudança na própria natureza do trabalho, que deixa de significar fazeres, para passar a significar intervenção quando os equipamentos ou sistemas apresentam funcionamento anormal que exige atuação qualificada do trabalhador. Como afirma o autor, o trabalho passa a significar enfrentar eventos, o que desloca o eixo da competência de memorizar procedimentos a serem repetidos para a competência de enfrentar situações anormais, com maior ou menor grau de previsibilidade.

No limite, competência passa a ser a capacidade para resolver situações não previstas, até mesmo desconhecidas, para o que se articulam conhecimentos tácitos e científicos adquiridos ao logo da história de vida, através das experiências de formação escolar e profissional e da experiência laboral. Mais do que à memorização, esta nova forma de conceber a competência remete à criatividade, à capacidade comunicativa, à educação continuada.

A partir destas mudanças se estabelece uma aparente contradição: quanto mais se simplificam as tarefas, mais se exige conhecimento do trabalhador, e não apenas tácito. Ao contrário, a crescente complexificação dos instrumentos de produção, informação e controle, nos quais a base eletromecânica é substituída pela base microeletrônica, passam a exigir o desenvolvimento de competências cognitivas complexas e de relacionamento, tais como análise, síntese, estabelecimento de relações, criação de soluções inovadoras, rapidez de resposta, comunicação clara e precisa, interpretação e uso de diferentes formas de linguagem, capacidade para trabalhar em grupo, gerenciar processos para atingir metas, trabalhar com prioridades, avaliar, lidar com as diferenças, enfrentar os desafios das mudanças permanentes, resistir a pressões, desenvolver o raciocínio lógico-formal aliado à intuição criadora, buscar aprender permanentemente, e assim por diante.(Kuenzer, 1999)

Mesmo quando o trabalho é simplificado, o elevado custo de um investimento tecnologicamente sofisticado e as demandas de competitividade exigem trabalhadores potencialmente capazes de intervir critica e criativamente quando necessário, não só assegurando índices razoáveis de produtividade, através da observação de normas de segurança e da obtenção de índices 
mínimos de desperdício, de paradas, de re-trabalho e de riscos, mas também otimizando o sistema.

Se para o desenvolvimento de competências nas formas tayloristas/fordistas de organização e gestão do trabalho bastava a prática, agora passa a ser estratégico o desenvolvimento das competências cognitivas complexas, que exige relação com o conhecimento sistematizado através do trabalho intelectual, de modo a desenvolver o raciocínio lógico formal, as capacidades comunicativas e a criatividade; ou seja, ampliação da escolaridade.

Esta é a primeira significativa aprendizagem dos trabalhadores nas relações de trabalho: o conhecimento tácito não é mais suficiente. Há necessidade de educação básica e profissional sistematizada, com o que passam a ser valorizados e buscados os processos especificamente pedagógicos. Ao contrário do que ocorria nos processos tayloristas fordistas, já não é suficiente a experiência do trabalho.

É importante destacar, contudo, que no regime de acumulação flexível não desaparece a relevância do conhecimento tácito em nome da supremacia do conhecimento científico, mas sim se reestabelece a dialética entre teoria e prática, passando a competência a assumir dimensão práxica. Como têm mostrado as pesquisas que vêm sendo realizadas pela autora, passou-se a conceber competência comoa capacidade de agir, em situações previstas e não previstas, com rapidez e eficiência, articulando conhecimentos tácitos e científicos a experiências de vida e laborais vivenciadas ao longo das histórias de vida. Esta concepção de competência vincula-se à ideia de solucionar problemas, mobilizando conhecimentos de forma transdisciplinar a comportamentos e habilidades psicofísicas, e transferindo-os para novas situações; supõe, portanto, a capacidade de atuar mobilizando conhecimentos”. (Kuenzer, 2002)

Esta forma de conceber competência a partir das novas demandas do mundo do trabalho traz várias consequências para a discussão das relações entre setor produtivo e as instituições responsáveis pela educação profissional. A primeira delas diz respeito ao deslocamento da centralidade do conhecimento tácito, estruturante da concepção de competência no taylorismo/fordismo, para a centralidade do trabalho intelectual, com suas consequências relativas ao domínio dos processos de comunicação através da apropriação das diferentes linguagens. 
Assim, restam superados os processos de educação profissional que tinham como eixo o aprendizado de modos de fazer, desvinculados do domínio da teoria que fundamenta os processos de trabalho que se constituem em objeto dos cursos; ao mesmo tempo, a educação profissional passa a se articular de forma cada vez mais intensa à educação básica, que passam a buscá-la de forma intensiva.

Do ponto de vista da formação profissional, as necessidades de qualificação são deslocadas do plano individual para o plano institucional, uma vez que o desenvolvimento de competências passa a ser uma dimensão estratégica para a competitividade. $E$, respondendo às novas características da organização e gestão das plantas produtivas, em particular no que tange à produção puxada pela demanda, a exigir uma organização flexível, e neste sentido, peculiar, as empresas passam a buscar programas pedagógicos customizados.

Ao passar a integrar as estratégias de competitividade, a formação profissional passa a ser um ponto de articulação entre os interesses dos trabalhadores e as demandas de acumulação do capital; as pesquisas evidenciam que os trabalhadores passam a buscar o domínio das teorias que regem os processos de trabalho que executam, justificado pela necessidade de cumprimento das metas de produtividade, a ser viabilizada por um maior domínio sobre as novas tecnologias na perspectiva da permanência no emprego, mas também de trabalho com segurança e confiabilidade. Do ponto de vista da vida social e familiar, defendem o direito a ter acesso ao conhecimento como forma de participação mais efetiva nas relações sociais e na educação dos filhos.

Já as empresas reconhecem que os imperativos de competitividade passam a exigir cada vez mais o desenvolvimento de competências cognitivas complexas que articulam conhecimentos científicos e tácitos, cujo desenvolvimento implica em processos educativos que integrem os espaços formativos às práticas laborais.

Solidamente fundamentada sobre a educação básica, a competência não repousa mais sobre a aquisição de modos de fazer, deixando de ser concebida, como o faz o taylorismo/fordismo, como conjunto de atributos individuais, predominantemente psicofísicos, centrados nos modos de fazer típicos do posto de trabalho. Ao contrário, passa a ter reconhecida a sua dimensão social e ser 
concebida como resultante da articulação de diferentes elementos, através da mediação das relações que ocorrem no trabalho coletivo, resultando de vários determinantes subjetivos e objetivos, como a natureza das relações sociais vividas e suas articulações, escolaridade, acesso a informações, domínio do método científico, riqueza, duração e profundidade das experiências vivenciadas, tanto laborais quanto sociais, acesso a espaços, saberes, manifestações científicas e culturais, possibilidade de exercer autonomia e criatividade, de participar da definição das normas e das decisões que afetam as atividades, e assim por diante. (Machado, 1996)

A essa dimensão positiva agrega-se a sua contradição: a par da necessidade de expansão da escolaridade e da integração entre conhecimento tácito e científico nas trajetórias de vida e de trabalho, no campo do capital a demanda pelo desenvolvimento de modelos de gestão e de desenvolvimento que conduzam, através de novas formas de disciplinamento, à conformação de novas subjetividades, flexíveis, polivalentes e permanentemente educáveis como forma de resposta à instabilidade derivada do caráter dinâmico da produção do conhecimento na contemporaneidade, sem perder o controle sobre as formas de reprodução ampliada, onde a extração de mais-valia, agora derivada da exploração combinada de diferentes formas de trabalho, continua determinante.

O que o discurso da pedagogia da acumulação flexível não revela é que, ao destruírem-se os vínculos entre capacitação e trabalho pela utilização das novas tecnologias, que banaliza as competências, tornando-as bastante parecidas e com uma base comum de conhecimentos de automação industrial, a par da estratégia toyotista de definir a produção pela demanda, o mercado de trabalho passa a reger-se pela lógica dos arranjos flexíveis de competências diferenciadas. (Kuenzer, 2007)

Diferentemente do que ocorria no taylorismo/fordismo, onde as competências eram desenvolvidas com foco em ocupações previamente definidas e relativamente estáveis, a integração produtiva se alimenta do consumo flexível de competências diferenciadas, que se articulam ao longo das cadeias produtivas. Estas combinações não seguem modelos pré-estabelecidos, sendo definidas e redefinidas segundo as estratégias de contratação e subcontratação que são mobilizadas para atender à produção puxada pela demanda do mercado.

São combinações que ora incluem, ora excluem trabalhadores com TrabalhoNecessario - www.uff.br/trabalhonecessario; Ano 14, № 25/2016 
diferentes qualificações, de modo a constituir corpos coletivos de trabalho dinâmicos, por meio de uma rede que integra diferentes formas de subcontratação e trabalho temporário e que, ao combinar diferentes estratégias de extração de mais-valia, asseguram a realização da lógica mercantil.

Se há combinação entre trabalhos desiguais e diferenciados ao longo das cadeias produtivas, há também demandas diferenciadas, e desiguais, de qualificação dos trabalhadores, que podem ser rapidamente atendidas pelas estratégias de aprendizagem flexível, o que permite que as contratações sejam definidas a partir de um perfil de trabalhador com aportes de educação geral e capacidade para aprender novos processos, e não a partir da qualificação.

Daí o caráter "flexível" da força de trabalho; importa menos a qualificação prévia do que a adaptabilidade, que inclui tanto as competências anteriormente desenvolvidas, cognitivas, práticas ou comportamentais, quanto a competência para aprender e para submeter-se ao novo, o que supõe subjetividades disciplinadas que lidem adequadamente com a dinamicidade, com a instabilidade, com a fluidez.

O discurso da necessidade de elevação dos níveis de conhecimento e da capacidade de trabalhar intelectualmente, quando adequadamente analisado a partir da lógica da acumulação flexível, mostra seu caráter concreto: a necessidade de ter disponível para consumo, nas cadeias produtivas, força de trabalho com qualificações desiguais e diferenciadas que, combinadas em células, equipes, ou mesmo linhas, atendendo a diferentes formas de contratação, subcontratação e outros acordos precários, assegurem os níveis desejados de produtividade, por meio de processos de extração de mais-valia que combinam as dimensões relativa e absoluta.

Esta forma de consumo da força de trabalho ao longo das cadeias produtivas aprofunda a distribuição desigual do conhecimento, onde, para alguns, dependendo de onde e por quanto tempo estejam integrados nas cadeias produtivas, se reserva o direito de exercer o trabalho intelectual integrado às atividades práticas, a partir de extensa e qualificada trajetória de escolarização; o mesmo não ocorre com a maioria dos trabalhadores, que desenvolvem conhecimentos tácitos pouco sofisticados, em atividades laborais de natureza simples e desqualificada e são precariamente qualificados por processos rápidos de treinamento, com apoio nas novas tecnologias e com os princípios da TrabalhoNecessario - www.uff.br/trabalhonecessario; Ano 14, № 25/2016 
aprendizagem flexível.

Em resumo, a pedagogia da acumulação flexível tem como finalidade a formação de trabalhadores com subjetividades flexíveis, tanto do ponto de vista cognitivo quanto ético, por meio de educação geral complementada com capacitações profissionais disponibilizadas de forma diferenciada por origem de classe, que os levem a exercer, e aceitar, de forma natural, as múltiplas tarefas no mercado flexibilizado. Ser multitarefa, neste caso, implica exercer trabalhos disponibilizados pelo mercado, para os quais seja suficiente um rápido treinamento, a partir da educação geral, seja no nível básico, técnico ou superior. Para a maioria dos trabalhadores, significará exercer trabalhos temporários simplificados, repetitivos e fragmentados.

\section{A formação de subjetividades flexíveis}

Além das novas aprendizagens promovidas pela dinamicidade do desenvolvimento científico-tecnológico que resultou na nova base técnica de natureza microeletrônica, o capital tem como desafio desenvolver novas subjetividades, flexíveis, que se submetam às novas formas de exploração do trabalho, agora predominantemente intelectualizado, para o que mobiliza novas formas de disciplinamento mediante processos ampla e especificamente pedagógicos, também denominados flexíveis. A seguir, serão apresentadas algumas das aprendizagens que os processos pedagógicos que integram as relações sociais e de trabalho, promovem. Essas aprendizagens derivam-se da negação da práxis como possibilidade de transformação, princípio que fundamenta as teorias pós-modernas.

Do ponto de vista dessas teorias, o conhecimento é uma impossibilidade histórica, uma vez que ao pensamento humano é impossível apreender a realidade, porque está demarcado por diversidades culturais; assim, as interpretações são diversas, sendo verdadeiras apenas no contexto cultural que Ihe deu origem. O que há são interpretações, narrativas atreladas à prática cotidiana, reduzindo-se o conhecimento à linguagem, do que decorre que a teoria se constrói mediante o embate de discursos intersubjetivos, ao nível da superestrutura; ou seja, pelo confronto de discursos, e não pelo confronto entre pensamento e materialidade. Essa afirmação, ao negar que o conhecimento 
resulta da relação entre teoria e prática, entre trabalho intelectual e atividade, põe por terra a concepção de práxis.

A partir dessa concepção, definem-se os contornos da subjetividade flexível, objeto dos processos pedagógicos de formação que visam a reprodução ampliada do capital; assim, no cotidiano das relações que os trabalhadores vivem no trabalho e na sociedade, vão se consolidando as novas aprendizagens que configuram o princípio educativo do trabalho na acumulação flexível. Sem a pretensão de esgotar a discussão, são apresentadas algumas dentre as que mais têm se destacado na nova pedagogia do trabalho.

A relação com o conhecimento fundada no pragmatismo utilitarista: em que pese a acumulação flexível demandar a ampliação da escolaridade e a apropriação do conhecimento científico-tecnológico necessário à operação de processos e sistemas de base microeletrônica, essa relação se dá a partir da epistemologia da prática: só merece ser conhecido o que é útil, o que tem aplicabilidade imediata, fortalecendo-se uma relação meramente interessada com o conhecimento e com a cultura; o processo cognitivo plasma-se no interior de limites que se definem pela eficácia, pela manipulação do tópico e do imediato. O conhecimento limita-se à prática imediata e reduz-se à experiência sensível, aos limites do empírico enquanto fim em si mesmo, e não enquanto ponto de partida e ponto de chegada da produção do conhecimento na perspectiva da transformação. (Moraes, 2003);

O presentismo e a individualização: a negação da praxis enquanto possibilidade de transformação anula os projetos, as possibilidades, e a historicidade: o que vale é o presente. A experiência histórica é substituída pela experiência do momento; as organizações históricas e suas experiências acumuladas são substituídas pelo ativismo, onde a sensação do ineditismo nas ações voluntaristas torna-se a referência maior das escolhas das posturas e das posições políticas. (Debord, 2013); se não há história, não há valores, nem princípios ou fundamentos e não há futuro; só o presente, que deve ser vivido em sua completude; reforça-se o individualismo, reduzindo-se a sociedade à interação entre indivíduos e as relações sociais são reduzidas ao plano individual, a escolhas pessoais; consequentemente, não há teorias sociais, pois estas são ilusões que TrabalhoNecessario - www.uff.br/trabalhonecessario; Ano 14, № 25/2016 
disfarçam interesses particulares; em que pese o discurso sobre a complexidade, a totalidade passa a ser um recurso metodológico impossível, pois não há como estabelecer relações causais entre fenômenos sociais;

A totalidade é substituída pela fragmentação: a relação com o conhecimento mediada pelas novas tecnologias se caracteriza pela fragmentação caleidoscópica propiciada pelos avanços tecnológicos, amplamente disponibilizados em equipamentos de todos os tipos e preços; ao navegar no hipertexto, perde-se o foco e esquece-se do objetivo inicial com facilidade; desta forma, as informações, muitas de qualidade discutível tanto do ponto de vista científico quanto ético, se sucedem rapidamente; perde-se a capacidade de reflexão e de crítica, em nome do espetáculo;

A homogeinização das identidades, resultante das novas formas de controle exercidas pelo capital: o controle das massas se exerce pelo poder concentrado que impõe, pelas novas tecnologias de informação e comunicação, um padrão de valores que regulam toda a sociedade pela conformação de uma única identidade; assim, os valores são criados pelo poder (do capital), que apresenta como universal seus interesses particulares; induz-se a uma falsa liberdade de escolha pela superprodução de mercadorias cada vez mais tecnologicamente sofisticadas, cujo consumo também responde a padrões de comportamento favoráveis ao processo de acumulação; sob o discurso da heterogeneidade, do respeito às diferenças, esconde-se 0 processo de homogeneização cultural ( Debord, 2013);

- A redução do real ao virtual, com a consequente redução da ética à estética, que conduz à banalização da violência: a integração de todos os tipos de mensagens em um padrão cognitivo comum, reduz a distância mental entre as várias fontes de envolvimento cognitivo e sensorial: "diferentes modos de comunicação tendem a trocar códigos entre si, criando um contexto semântico multifacetado composto de uma mistura aleatória de vários sentidos, programas educativos parecem videogames; noticiários são construídos como espetáculos audiovisuais, julgamentos parecem novelas (Castels, p. 394); o que a mídia reproduz é a verdade; os ídolos midiáticos definem formas de linguagem, posturas e padrões de consumo; a ética é substituída pela estética e o que atrai e motiva é a conjugação de movimentos, cores, formas e sons, integrados pelas 
mídias de forma cada vez mais espetacular; a estetização da violência e a banalização das injustiça fazem parte da sociedade do espetáculo (Debors, 2013);

- A banalização do esforço, a passividade cognitiva, a perda de interesse pela leitura, características cada vez mais presentes entre participantes de todos os níveis e modalidades educativas; aprender depressa e sem esforço, é o desejo permanentemente manifesto; para atendê-lo, desenvolve-se uma pedagogia mercantilizada que oferece opções de curta duração, baixo custo e reduzida qualidade, presenciais e à distância, onde o pouco esforço intelectual é recompensado com um certificado tão vazio de significado quanto incapaz de facilitar a inclusão;

- A competitividade e o individualismo em substituição à solidariedade e ao trabalho coletivo: com a diminuição das possibilidades de acesso a ocupações qualificadas e formalizadas no mundo do trabalho a partir do caráter estruturalmente desempregador do regime de acumulação flexível, a par da precarização e da intensificação do trabalho submetido à lógica produtivista, a competitividade passou a ser uma das características definidoras da subjetividade flexível, em contraposição aos laços de solidariedade que marcavam as relações de trabalho na modernidade; junto com a competitividade, a crescente individualização do trabalho, com severos impactos no sofrimento do trabalho que levam, desde as mais leves patologias, ao crescimento dos índices de suicídio no espaço de trabalho; ao mesmo tempo, aumentam os índices de assédio moral, sempre em nome da produtividade; esse esgarçamento das relações de trabalho, segundo Dejour, resulta das novas formas de organização e gestão do trabalho segundo o paradigma toyotista, cujo objetivo é o aumento da produtividade a qualquer preço, como forma de assegurar a acumulação do capital;

A naturalização da perda dos direitos trabalhistas a partir da flexibilização da legislação trabalhista, que passa a reconhecer novas formas de acordo; no caso brasileiro, essas novas formas se objetivam na proposta de lei sobre a terceirização, em tramitação no Senado Federal, que poderá incluir as atividades-fim e que institucionaliza a precarização do trabalho, e à flexibilização da CLT em curso, que possibilita as negociações coletivas para tratar de temas como salário e extensão da jornada dos trabalhadores; com essas medidas, 
fragiliza-se a dimensão protetiva e mediadora da Justiça do Trabalho, tornando os trabalhadores mais vulneráveis à exploração do trabalho; a ampliação da vulnerabilidade estimula a competitividade e a degradação da ética no trabalho, a resistência à intensificação do trabalho, à pressão e ao estresse; cada vez mais a vida pessoal se confunde com a profissional; ampliam-se os índices de adoecimento,inclusive pela negação dos sintomas pelo trabalhador, que teme ser demitido ao manifestar necessidade de tratamento; ou seja, a conformação da subjetividade flexível reforça, pelo trabalhador, a dimensão de artífice da própria exploração.

\section{Para a reflexão: ainda existem espaços e processos formativos contra-hegemônicos?}

As novas aprendizagens que o trabalhador tem feito no trabalho, no âmbito do projeto pedagógico da acumulação flexível, trazem à tona a questão dos espaços formativos comprometidos com a crítica que objetive, a partir do desvelar da ideologia, a construção de um projeto contra-hegemônico, que aponte para a emancipação dos que vivem do trabalho.

A dimensão que mais se evidencia nesse debate é que o trabalhador, cada vez mais precisará ter um amplo domínio sobre a ciência, sobre o trabalho e sobre a cultura, agora mediados por novas e diferentes formas de linguagem que se integram segundo os interesses da acumulação capitalista; esse domínio é necessário para que o trabalhador possa exercer a diferenciação crítica sobre seus usos e finalidades não explicitadas, assim como autonomia para trabalhar intelectual e eticamente, tarefa complexificada pelas formas desiguais de acesso ao conhecimento, à cultura e ao desenvolvimento de competências cognitivas complexas. A questão que se coloca é em que espaços essa formação poderá ocorrer.

A primeira instância superestrutural responsável por essa tarefa é a escola; contudo, desnecessário se faz uma análise mais profunda para demonstrar a crescente invasão das escolas públicas pela lógica mercantil, orquestrada pelos setores empresariais com a anuência do Estado. Em decorrência, as diretrizes curriculares, em particular as do ensino médio e do ensino superior, têm passado por processos de flexibilização, tal como os processos de aprendizagem, apesar

TrabalhoNecessario - www.uff.br/trabalhonecessario; Ano 14, № 25/2016 
dos acirrados enfrentamentos das entidades e movimentos comprometidos com os trabalhadores. (Kuenzer, 2016) Um bom exemplo dessa afirmação é a proposta de reforma de ensino médio, constante do PL 6840/2013, recentemente imposto à sociedade por Medida Provisória, com o apoio do MEC, das empresas e do Conselho de Secretários de Educação.

A função formativa dos partidos de esquerda ficou praticamente neutralizada pelos problemas internos derivados de esquemas de corrupção, ampliados pelo interesse de desmobilização pelos partidos conservadores. Dentre os sindicatos mais aguerridos, muitos foram cooptados pelo projeto burguês, por razões que vão das necessidades de sobrevivência aos interesses individuais, econômicos e políticos, de seus dirigentes.

Como agregar esforços e construir estratégias eficientes para enfrentar essa nova, e dura realidade, construindo novos espaços formativos orientados pelos interesses dos trabalhadores, é a questão que nos mobiliza, neste momento histórico.

\section{Referências Bibliográficas}

CASTELS, M. A sociedade em rede. São Paulo, Paz e Terra, 1999.

DEBORD, G. A sociedade do espetáculo, 2013, eBooksBrasil.com

HARVEY, D. Condição pós-moderna. São Paulo, Loyola, 1992, p. 135-140.

KUENZER. A.A Pedagogia da Fábrica: as relações de produção e a educação do trabalhador. São Paulo, Cortez, 1985.

. Educação profissional: novas categorias para uma pedagogia do trabalho. Boletim Técnico de Senac, Rio de Janeiro, v.25, n.2, maio/ago, 1999.

Conhecimento e competências no trabalho e na escola. Rio de Janeiro, Boletim Técnico do SENAC, v. 28, n.2, maio/ago., 2002, p. 8.

Competência como Práxis: os dilemas da relação entre teoria e prática na educação dos trabalhadores. Boletim Técnico do Senac, Rio de Janeiro, v.29, n.1, jan/abr., 2003.

- Da dualidade assumida à dualidade negada; o discurso da flexibilização justifica a inclusão excludente. Educação e Sociedade, v28, p.11531178, 2007. 
KUENZER, A. Z; ABREU, C; GOMES, C. A articulação entre conhecimento tácito e inovação tecnológica: a função mediadora da educação. Revista Brasileira de Educação. Revista Brasileira de Educação, v. 12, p. 1-16, 2007.

GRAMSCI, A. Maquiavel, a política e o Estado Moderno. Rio de Janeiro, Civilização Brasileira, 1978.

MACHADO, Lucília. Qualificação do trabalho e relações sociais. In: Gestão do trabalho e formação do trabalhador. Belo Horizonte, MCM, 1996.

MARX e ENGELS. A ideologia alemã. Portugal, Martins Fontes, s.d.

MORAES. M. C. M. M. (org.) Iluminismo às Avessas: produção de conhecimento e políticas de formação docente. Rio de Janeiro: DP\&A, 2003.

ZARIFIAN, P. Objetivo competência: por uma nova lógica. São Paulo, Atlas, 2001, p.41 